\title{
Factors Affecting Pupils' Absenteeism at Felicormfort Junior High School (JHS) in Cape Coast, Ghana
}

\author{
Felix Senyametor ${ }^{1}$, Emmanuel Kofi Gyimah ${ }^{1} \&$ Vincent Mensah Minadzi ${ }^{1}$ \\ ${ }^{1}$ College of Distance Education, University of Cape Coast, Ghana \\ Correspondence: Felix Senyametor, College of Distance Education, University of Cape Coast, Ghana.
}

Received: July 24, 2018

doi:10.5539/jel.v7n6p138
Accepted: September 5, $2018 \quad$ Online Published: September 27, 2018

URL: https://doi.org/10.5539/jel.v7n6p138

\begin{abstract}
This study aimed at finding out factors affecting pupils' absenteeism at Felicomfort JHS at Amamoma within the University of Cape Coast, Ghana. The total population was 145 covering the JHS1, JHS2, JHS3 pupils and teachers of the school. Purposive sampling technique was used to select 34 respondents. These were made up of 10 out of 15 teachers, 10 parents out of 53 and 14 pupils out of their accessible population of 56 . Pretest, posttest, questionnaires and interviews were used to collect data from respondents. Case study design was used for the study and data analysis was done, using mean values, frequency and percentage counts with the Predictive Analytical Software (PASW) version 21. Key findings of the study indicated that 71.4 percent of absenteeism was due to teachers' inability to care and find out from pupils the cause of their absenteeism, while 70 percent of respondents indicated that parental lack of care was the major cause of their absenteeism. However, majority (10) of respondents $(71 \%)$ disagreed that pupils' attitudes were part of the contributory factors to their habitual absenteeism. The overall percentage mean $(58 \%)$ representing 8 of the pupils discounted teacher factor as responsible for their absenteeism. It was recommended that government through the District Assemblies offer some financial assistance to poor and single parents to enable them to adequately cater for their wards at school.
\end{abstract}

Keywords: motivation, absenteeism, basic school

\section{Introduction}

Regular school attendance is vital for pupils' academic and social development. Therefore, pupils' consistent absence from school adversely affects their social and academic progress. According to Loren (2011), absentees miss out on critical stages of lessons and social interactions that are necessary for solid academic development with their peers. This, according to her, could result in low self-esteem, social isolation, and dissatisfaction that could result in school dropout.

School pupils' absenteeism also affects the teacher's ability to present lessons in a sequential and organised way. This can have a deleterious effect on the progress of all the students in the class. Families of habitually absent students can also suffer. For a poverty-stricken family, it may mean a continuation of the poverty and unemployment cycle that may run in the family. This also contributes to family conflicts (Loren, 2011).

According to Loren (2011, p. 2),"society suffers when school-age children are not in school. These children may hang out on the streets. Since they have nothing to do, they resort to petty crimes like stealing other people's belongings and property". Loren further added that some absentees may become even addicted to drugs or engage in other destructive behaviours and grow up to become liability to society as a whole.

It is the aim of every school to lessen, if not eradicate, absenteeism among its students. One way of addressing this problem is to identify the causes of absenteeism. Once they are singled out, understood, and analyzed, they could be addressed with specific interventions. This will eventually result in good performance of the students, teachers, and the school in general.

Habitual absenteeism may be due to lack of intrinsic motivation on the part of the absentee, peer influence and or socio-cultural factors (Scavenger, 2011). Whatever the precipitating factors are, the phenomenon has become a big problem in many schools in Ghana and beyond. Felicomfort Junior High School (JHS) in Cape Coast is one of the schools in Ghana experiencing absenteeism of pupils. Out of the total population of 56 Junior High School 1 and 2 pupils, 14 of them were habitual absentees. This baseline data was obtained from review of pupils' attendance register and the details are presented in table 1. 
Table 1. Results of pupils' attendance at Felicomfort JHS for two weeks

\begin{tabular}{ccc}
\hline Pupil & Attendance & Percentage (\%) \\
\cline { 2 - 3 } 2 & $2 / 10$ & 20 \\
3 & $4 / 10$ & 40 \\
4 & $1 / 10$ & 10 \\
5 & $3 / 10$ & 30 \\
6 & $4 / 10$ & 40 \\
7 & $5 / 10$ & 50 \\
8 & $3 / 10$ & 30 \\
9 & $2 / 10$ & 20 \\
10 & $2 / 10$ & 20 \\
11 & $1 / 10$ & 10 \\
12 & $2 / 10$ & 20 \\
13 & $4 / 10$ & 40 \\
14 & $1 / 10$ & 10 \\
\hline
\end{tabular}

Source: Field Data, 2017.

The mean percentage (26\%) and total school attendance of 3 days by pupils in Table 5 portrays a significant trend of pupils' absenteeism.

It appears that there has not been any empirical research into the phenomenon in the existing literature on the factors affecting pupils' absenteeism at the Felicomfort JHS. It is against this background that this study was undertaken to examine the factors responsible for habitual absenteeism at the Felicomfort Junior High School (JHS) one and two in the central region of Ghana.

\subsection{The Needs Theory, Reinforcement (Provision of Needs or Rewards) and Pupils' Absenteeism}

In 1943, Abraham Maslow in a seminar paper, titled “A Theory of Human Motivation” proposed that a person's motivational needs could be arranged in a hierarchical order, which is based on the following four major assumptions (as cited in Lussier \& Achua, 2001):

1) Only unmet needs motivate.

2) People's needs are arranged in order of importance (hierarchy) going from basic to complex needs.

3) People will not be motivated to satisfy a higher level need unless the lower level need has been at least minimally satisfied.

4) People have five classifications of needs, which are presented in hierarchical order from low to high level of needs.

Inherent in this hierarchical order of needs is the fact that once a given level of need is satisfied, it no longer serves to motivate rather the next higher level of need has to be activated in order to motivate the individual. The hierarchy of needs theory proposes that people are motivated and reinforced through five levels of needs, which are; physiological, safety, belongingness, esteem, and self-actualization.

Physiological needs: These are the basic human needs such as food, clothing, sex, shelter, relief or avoidance of pain that sustain life. Until these basic needs are satisfied to the degree needed, for sufficient operation of the body, majority of a person's activity will probably be at this level and other needs will provide little or no motivation and reinforcement (Johnmarshall, 2009). Pupils are encouraged to attend school regularly when all their physiological needs including food are provided (Lussier \& Achua, 2001).

Safety or Security Needs: These needs are essential, the desire to be free of the fear of physical danger and the deprivation of the basic physiological needs. This is a need for self-preservation and the concern for the future. If an individual's safety or security need is in danger, other things seem unimportant. Loren (2011), buttressing pupils' safety opined that Safety school and home environments are prerequisites to reducing pupils' absenteeism.

Social or Affiliation (belongingness) Needs: Social needs include the need to belong and be accepted by people. Love and care from parents and teachers are critical for pupils' regular attendance and academic progress (Johnmarshall, 2009; Lussier \& Achua, 2001)

Esteem Needs: The esteem needs represent the individual's ego status, self-esteem, recognition for 
accomplishment from others. The satisfaction of these needs produces feelings of self-confidence, prestige, power and control. When school pupils are made by their teachers and parents to feel that they are useful and their act of school attendance is reinforced or rewarded, they will no doubt continue to be regular at school.

Self-Actualization: This is the need to maximize one's potential whatever, it may be as Maslow expressed it, "What a man be, he must be". It is also the desire to become what one is capable of becoming (Aggarwal, 1995). This implies that if school pupils' potentials are identified by teachers and parents early enough, they could be helped and encouraged through counselling and assurance to become whatever they want to become in future. This will be very reinforcing for them to continue daily school attendance without breaks.

\subsection{School and Home Environment}

Loren (2011), investigated into the problem of Grade Six students pupils' absenteeism at Zapote Elementary School. The study was conducted against the perceived harmful effects of absenteeism on the academic progression and future prosperity of the pupils.

Data were collected using interviews and questionnaires developed on a five-point scale to elicit students' views about factors militating against their ability to be regular in school. Mean values, frequency and percentage counts were used in the analysis and interpretation of data collected within the 2010/2011 academic year.

Loren's (2011) study, revealed that causes of students' absenteeism was related to factors like physical (danger caused as a result of walking to school, school being very far away from home and the like), health, pupils' personal attitudes, teacher and classroom related issues, and parental related factors. The study found that teacher and pupils' attitudes contribute 75 percent of pupils' absenteeism, parental (parents' inability to provide needs of their wards) and home related constitutes 81 percent of absenteeism. Classroom environmental issues also contribute 70 percent of the causes of pupils' absenteeism. Going forward regarding curbing the problem of absenteeism, the study recommended among others the following:

1) Education of students on the importance of education; ensuring that classroom atmosphere is conducive for learning and the education of parents on the need to adequately provide the needs of their wards in order for them to be regular at school.

2) Teachers should give extra attention to pupils who lag behind in classroom lessons.

3) All school pupils should be counselled to realise that their academic success and prosperity in future is very much dependent on their positive attitude towards school.

In a related study, according to Demir, Akman and Karabeyoglu (2015), the factors associated with absenteeism are multi-faceted and could be categorised into three major areas: individual, family and schools.

Individual (personal) Factors: Research shows that absenteeism increases by seniority in high school and most usually occurs at 15 years (Demir, Akman \& Karabeyoglu, 2015). Pupils who normally absent themselves from school do not feel comfortable and safe in school. They feel academically or socially inadequate, find classes boring and their positive experiences related to school are less as compared to those who always attend school (Clarke, 2008; Corville-Smith, Ryan Adams, \& Dalicandro, 1998; Williams, 2001). According to Heyne Gren-Landell, Melvin and Gentle-Genitty (2018), some other individual factors accounting for pupils' absenteeism include not wanting to get up in the morning, receiving strict punishment, sleeping late and not completing homework given by teachers. Others are: Being in a class that is one above or one below the regular class level, transferring to another school in the middle or the beginning of the school year, feeling extreme test pressure, feeling constantly ill, and having siblings who are regularly absent. Clark (2008), also added that, some pupils absent themselves from school when the courses in school are difficult and monotonous.

Family (parental) factors: According Clark (2008), parents of pupils have enormous impact on school attendance. He revealed that family's socio-economic background; family's need for student to work; parenting strategies; psychological problems; support or neglect; alcohol or drug problems and parental criminal behaviour also impact on pupils' absenteeism. Other family related factors include divorce; inter-parent conflicts; family structure, such as a single parent, interest or control level for the pupils' behaviour, parents with low level of educational background, negative past school experiences; lack of participation in school or not understanding procedures; and not providing environment for the student to do homework (Corville-Smith, Ryan Adams, \& Dalicandro, 1998, Rood, 1989; Corley, 2012; Gentle-Genitty, 2008, Eastman et al., 2007, Reed, 2000) (as cited in Demir, Akman \& Karabeyoglu, 2015). The level of respect the family has for education is seen as a role model for their school-age wards. They found that parental control and family related factors of absenteeism account for $22 \%$. Loren (2011), also found $81 \%$ of absenteeism being parental and family related. 
Parents no doubt have the duty to ensure that their wards attend school regularly. In fact, home conditions including proper control of children play a major role in aiding pupils to be regular at school. Poor family control is one of the most important factors accounting for school absenteeism (Pehlivan, 2006). Family control, according to Cetin and Cok (2011), refers to parents' knowledge about their wards activities, friends and the information regarding their whereabouts. Careless parents usually are not concerned about the success of their children. They do not assist their wards in solving the problems at school and they rarely attend Parent-Teacher Association (PTA) meetings, and do not normally put in place a disciplined home environment for their wards. School pupils of today are much less controlled than their parents were in the past. As well as lack of control and lack of monitoring, some parents shirk their responsibilities to ensure regular school attendance by their wards. By so doing, they are supporting and justifying the absenteeism (Demir et al, 2015).

School factors: School-related factors influence students' decisions toward school attendance. School policies, attitude and rules regarding absenteeism influence pupils' decision to whether or not be regular at school. According to Robinson (2009), schools' procedures are inconsistent and do not produce meaningful results in reducing absenteeism. Students are not receiving clear messages from the school about the importance of attendance. Tolerant policies or lack of firm implementation of existing policies give the wrong message to students and parents about the importance of regular school attendance (Clarke, 2008). Wall (2000), revealed that inconsistency of school policies, lack of meaningful results and poor school record keeping have a negative effect on pupils' regular school attendance. This according to Wall (2000) contributes 25 percent of pupils' absenteeism. According to Pehlivan (2006), there are various reasons for absenteeism, but the most important of these reasons includes some pupils not liking the school, the school not being secure, climate of tolerance for bullying, students would opt not to be in school.

In a school environment where students do not feel a commitment to school, they would not want to attend, resulting in increased feelings of alienation. Hamm and Faircloth (2005), found that commitment to the school is formed by the pupil's perceptions about respect, love, care and attention they receive in the school. In the school environment where there is a perceived value for love and an emotional commitment, pupils would have a sense of security which will translate in increased regular school attendance. Demir, et al (2015), found that teacher and school environment related factors was the highest (83\%) factor responsible for pupils' school absenteeism.

\subsection{Statement of the Problem}

Absenteeism refers to willful nonattendance at work or school without any concrete reason. It entails either habitual evasion of work, school or willful absence as in a strike action or unrest. It does not include involuntary or occasional absence because of valid causes, or reasons beyond one's control, such as accidents or illness (Scavenger, 2011).

According to Abdul, Nauman and Majida (2017), in Pakistan the problem of school absenteeism was on the ascendancy. They found that on 15th of August, 2016 when schools were re-opened in Lahore, every television channel was making hue and cry about the absenteeism of students. Almost 80-90 percent of students did not bother to go to their institutions even after staying home two months on vacation. Even one of the schools recorded 121 absentees out of 1189 students and similar was the case all over some other secondary schools of Lahore. Some reasons, according to the findings of Abdul, et al (2017), accounting for absenteeism in Pakistan were: parents' inability to pay pupils' transport for school, money for food and learning materials. Pupils, on the other hand, according to the findings, were addicted to the social media, playing computer games and keeping bad companies who were not interested in schooling. The study however, could not capture teacher related factors accounting to pupils' absenteeism. This current study intends to cover this research gap.

Here in Ghana, Nkansah, Ninson, Owusu and Prempeh (2017), found 56 percent of pupils' absenteeism at Ebom-Bommfa Junior High School in the Bosome Freho District. The study revealed, teacher and pupils' related factors responsible for absenteeism of pupils. Nkansa et al (2017), however, did not explore parental factors which could be one of the major causes of pupils' absenteeism. This is another gap in research that this study aims to fill.

Felicomfort JHS in Cape Coast is no exception as far as pupils' absenteeism is concerned. Out of the total population of 56 Junior High School 1 and 2 pupils, 14 of them were habitual absentees (Felicomfort JHS, 2016). The headmaster of the school and the teachers lamented that the phenomenon was adversely affecting the academic performance of some of them. They wondered how this behavioural problem of the pupils could be curtailed to improve their school attendance. One wonders whether the same factors that were responsible for pupils' absenteeism in Loren (2011), Pakistan and Ebom-Bommfa Junior High School at the Bosome Freho District and others yet to be explored could be accounting for pupils' absenteeism at Felicomfort JHS at Cape Coast in Ghana too. This is the focus of this study. 


\subsection{Research Questions}

1) What are the personal related factors of Felicomfort JHS pupils' absenteeism?

2) What are the teacher related factors of pupils' absenteeism at Felicomfort JHS?

3) What are the parental related factors of pupils' absenteeism at Felicomfort JHS?

\section{Methodology}

\subsection{Research Design}

The case study design was used for the study. Data gathered from case study is usually largely qualitative, but it may also be quantitative (Spring, 1997). This design was considered appropriate because the study was designed to analyse, interpret and report the feelings and opinions of respondents related to the current status of the factors affecting pupils' absenteeism at the Felicomfort JHS 1 and 2 in Cape Coast.

\subsection{Population and Sample}

Sarantakos (1998) refers to population as the whole set of objects and events or group of people which are the objects of research and about which the researcher wants to determine some characteristics. Therefore, the target population was 213. This included 145 pupils of Felicomfort JHS at Amamoma in Cape Coast, their parents totaling 53 and 15 teachers. JHS students in the first and second years numbering 56, were made up of 29 males and 27 females, 10 parents and 15 teachers totaling 81 was the target population (Felicomfort JHS, 2016).

The sample for this study was 34 made up of 10 parents, 10 teachers ( 6 males and 4 males) purposively sampled. Furthermore, a total of 14 pupils ( 9 males and 5 females) were also purposively selected from their total population of 56 in the first and second years of the school. The JHS 3 pupils were not included in the study because they were writing their Basic Education Certificate Examination (BECE) at the time this study was being undertaken taking place. The pupils were purposefully sampled because; they were those battling with the problem of absenteeism and the focus of the study (Fraenkel \& Wallen, 2006). Teachers for JHS 1 and 2 were also randomly sampled.

\subsection{Data Collection Instrument}

Examination of pupils' attendance register, likert scale type of questionnaires for pupils and structured interview for parents were used to collect data for the study. Examination of the attendance register was done to select pupils who were consistently absenting themselves from school. The questionnaire was used to collect data from pupils and teachers because it was cost effective and good for the literate sample. The structured interview was considered appropriate for parents because most of them were illiterates. A pilot study was done at Kwakese Roman Catholic JHS 1 and 2 in the Cape Coast Municipality because the pupils there shared similar chacteristics with those at the Felicomfort JHS. The reliability coefficients of the questionnaires for pupils, teachers and parents were computed and presented in table 1 .

Table 2. Reliability of questionnaire for pupils and teachers and parents

\begin{tabular}{lc}
\hline $\begin{array}{l}\text { Reliability analysis of the } \\
\text { questionnaire }\end{array}$ & Coefficient of Cronbach Alpha \\
\hline Personal Factor & 0.72 \\
Teacher Factor & 0.83 \\
Parental Factor & 0.81 \\
\hline
\end{tabular}

Source: Field Data, 2017.

Table 2 indicates the factor wise reliability of the factors of absenteeism. The analysis ensured that items were internally consistent. The overall reliability of the tool was 0.79 . The highest reliability was reported for teacher factor $(0.83)$ and the lowest was reported for personal factor $(0.72)$.

\subsection{Data Collection Procedure}

Primary and secondary data were used. The primary data were collected through questionnaires and interview. Secondary data on the other hand, were collected through review of existing document like class registers. At the end of data collection, 9 male pupils, 5 female pupils, 10 teachers and 10 parents were captured. The return rate was therefore, 100 percent. 


\subsection{Ethical Issues}

The following ethical principles were followed in the conduct of the study: Informed consent, privacy, anonymity confidentiality and debriefing. In order to aid respondents to make informed decisions to participate in the study voluntarily, information on the possible risks and benefits of the research was communicated to them. This was done through the issuance of consent form to the respondents to fill. The form incorporated an introduction to the study, purpose of the study, description of any physical harm or discomfort, any invasion of privacy, threat to dignity as well as how they will be compensated in that case. Finally, the freedom to withdraw from the study too was explained to them.

Respect for anonymity, confidentiality and privacy: Personal identities of respondents were masked such that one could not link any personal response to any of them. Therefore, names of respondents were not required on the questionnaires administered.

Respondents were assured that any private information such as beliefs, attitudes, opinions and records, disclosed would not be shared with others without their knowledge or consent. In line with the principle of debriefing, objectives of the study, instruments and methodology aspects of the study were discussed with the respondents.

\subsection{Procedure for Data Analysis}

Data analysis was done in two ways. The first part dealt with analysis of the background characteristics of respondents and covered areas such as respondents' gender, status with parents and age. The second part was devoted to responses given by the respondents in accordance with the purpose of the study. Data collected were edited on the field, coded and entered into the computer. Research questions 1,2 and 3 were analyzed using mean values, frequency count and percentage analysis. Both descriptive and inferential statistics were used to analyse the research questions.

The issues were measured on a discrete four-point scale of 1- 4 ranging from strongly agree to strongly disagree. Based on this scale, a theoretical mean of 2.5 was derived and used to segregate respondents into categories of agree (2.5 or higher) and disagree (less than 2.5). The four-point scale was transformed into two-point scale. The responses agree and strongly agree were pulled together as agree, while strongly disagree and disagree were also pulled together as disagree. They were calculated with the help of Test Analytics for Surveys (TAfS), a tool of Predictive Analytic Software (PASW) Version 23, which is used for coding data and analysing verbatim responses to close-ended questionnaire and structured interview for parents to produces tables directly to enable data interpretation and discussion.

\section{Results}

The distribution of the sample (pupils) by gender was as follows: Nine (9) pupils representing 57.0 percent of pupils were males, while 5 representing 47 percent of them were females. Based on percentage distribution of the elements, it could be said that males mostly absented themselves from school. Furthermore, 7 (50.0\%) of the pupils were living with single parents, while $3(21.4 \%)$ and $2(14.3 \%)$ live with both parents, step parents and other family members. It therefore, appears that $50 \%$ of pupils' absenteeism could partly be attributed to single parenting. In terms of age of respondents, $11(78.6 \%)$ of the pupils were between the ages of 12-16 years while only $3(21.4 \%)$ were more than 20 years. The results show that the form 1 and 2 pupils at the Felicomfort JHS were relatively old.

\subsection{Research Question One: What Are the Personal Related Factors of Felicomfort JHS Pupils' Absenteeism?}

The research question one focused on how the attitudes of pupils affect their absence from school. Frequencies and percentages were used to analyse the data. Issues examined related to interest in their studies, attitude to work influence of friends and attention to studies. Other issues considered were reporting time to school and house chores. In all, seven items were used to answer this research question. 
Table 3. Pupils' personal related factors of absenteeism at Felicomfort JHS?

\begin{tabular}{lllll}
\hline Personal attitude & Agree & \multicolumn{3}{c}{ Disagree } \\
\cline { 2 - 5 } & No & $(\%)$ & No & $(\%)$ \\
\hline I am not interested in my studies. & 2 & 14.3 & 12 & 85.7 \\
I feel lazy. & 4 & 28.5 & 10 & 71.5 \\
My friends influence me to be absent from school. & 2 & 14.3 & 12 & 85.7 \\
I can't concentrate on my studies. & 2 & 14.3 & 12 & 85.7 \\
I don't wake up early to prepare for school. & 6 & 42.9 & 8 & 57.1 \\
I can't do my homework. & 4 & 28.6 & 10 & 71.4 \\
I always play computer games. & 4 & 28.6 & 10 & 71.4 \\
Percentage (\%) Mean & & 24 & & 76 \\
\hline
\end{tabular}

Source: Field Data, 2017

The results in Table 3 show the mean percentages of 24 and 76 being pupils related factors of absenteeism. Majority (12 pupils) representing 85.7 percent absented themselves from school because they could not concentrate on their studies at school, while 10-12 pupils (71.4\%-85.7\%) absented themselves from school due to lack of interest in studies, laziness, inability to do homework, playing of computer games and peer influence.

\subsection{Research Question Two: What Are the Teacher Related Factors of Pupils' Absenteeism at Felicomfort JHS?}

The second research question dealt pupils' understanding of lessons, attitude to teachers and teacher relationship with pupils. Eight items were analysed and the results presented in Table 4.

Table 4. Pupils' perceived teacher related factors of absenteeism at Felicomfort JHS?

\begin{tabular}{lllll}
\hline Teacher-Related Factors & Agree & \multicolumn{2}{l}{ Disagree } \\
\cline { 2 - 5 } & No & $(\%)$ & No & $(\%)$ \\
\hline My teachers always cane me. & 5 & 35.7 & 9 & 64.3 \\
I can't understand some lessons of my teacher. & 7 & 50.0 & 7 & 50.0 \\
I don't like my teacher. & 4 & 28.6 & 10 & 71.4 \\
My teacher is too strict. & 5 & 35.7 & 9 & 64.3 \\
My teacher doesn't care to find out from me about my absenteeism. & 10 & 71.4 & 4 & 28.6 \\
My teacher is not friendly. & 7 & 50.0 & 7 & 50.0 \\
My teacher does not show love and care for me. & 3 & 30.0 & 11 & 70.0 \\
My teacher doesn't advise me on the importance of education & 6 & 42.9 & 8 & 57.1 \\
Percentage Mean & & 43 & & 57 \\
\hline
\end{tabular}

Source: Field Data, 2017.

Table 4 shows the percentage mean of 57 (Majority of pupils) disagreeing that teacher related factors are responsible for their absenteeism at the Felicomfort JHS. However, the minority (43\%) admitted that teacher related factors were responsible for their absenteeism.

\subsection{Research Question Three: What Are the Teacher Related Factors of Pupils'Absenteeism at Felicomfort JHS?}

For the purpose of triangulation, teachers were also asked about things that they do to contribute to pupils' absenteeism at the school. Issues examined included teacher attitude and relationship with pupils, and interest in pupils' schooling. In all five items were analysed and the results are presented in Table 5.

Table 5. Teacher related factors of pupils' absenteeism at Felicomfort JHS

\begin{tabular}{|c|c|c|c|c|}
\hline \multirow[t]{2}{*}{ Teacher-Related Factors } & \multicolumn{2}{|c|}{ Agree } & \multicolumn{2}{|c|}{ Disagree } \\
\hline & No & $(\%)$ & No & $(\%)$ \\
\hline I always whip my pupils for wrong doing & 8 & 80.0 & 2 & 20.0 \\
\hline I make sure pupils understand my lessons every day & 9 & 90.0 & 1 & 10.0 \\
\hline I always care to find out from my pupils about their absenteeism & 5 & 50.0 & 5 & 50.0 \\
\hline I do not sometimes visit parents of absentees at their homes to find reasons of their wards' absenteeism & 8 & 80.0 & 2 & 20.0 \\
\hline I don't always advice my pupils about the importance of education & 3 & 30.0 & 7 & 70.0 \\
\hline Percentage Mean & & 66 & & 34 \\
\hline
\end{tabular}

Source: Field Data, 2017 
According to Table 5, the overall mean percentage of 66 percent (majority) shows that teachers were not responsible for pupils' absenteeism. However, 8 out of 10 teachers representing 80 percent reporting that pupils' absenteeism had to do with their failure to sometimes visit parents of absentees at their homes to find out reasons of their wards' absenteeism should raise some concerns.

\subsection{Research Question Four: What Are the Parental Related Factors of Pupils' Absenteeism at Felicomfort JHS? (Parental Provision of Education Related Materials for Pupils)}

With regard to the third research question of the study, emphasis was placed on how the parental related factors affected pupils' absenteeism at Felicomfort JHS. Seven items were used to elicit responses from the pupils. Issues considered included parents' provision of reinforcement in the form of school uniforms, money for food, transport and payment of fees for extra classes at school. Other issues examined were whether or not parents overburden pupils with household chores, provide them food to eat before going to school, advise them on the importance of education and assure them of catering for them at the SHS after successful completion of the JHS. The results are presented in table 6 .

Table 6. Pupils' perceived parental related factors of absenteeism at Felicomfort JHS

\begin{tabular}{lllll}
\hline Parental related cause of Absenteeism due to lack of reinforcement use & Agree & \multicolumn{2}{l}{ Disagree } \\
\cline { 2 - 5 } & No & (\%) & No & $(\%)$ \\
\hline My parents don't buy me school uniform. & 8 & 57.1 & 6 & 42.9 \\
I do too many household chores. & 8 & 57.1 & 6 & 42.9 \\
My parents don't give me money to buy food and pay for my extra classes at school. & 8 & 57.1 & 6 & 42.9 \\
I don't eat before going to school. & 12 & 85.7 & 2 & 14.3 \\
My house is too far from school and my parents don't give me money for transport. & 3 & 30.0 & 11 & 70.0 \\
My parents said they didn't have money to cater for me at the SHS even if I & 12 & 85.7 & 2 & 14.3 \\
successfully completed the JHS. & & & \\
My parents do not advise me on the importance of education. & & 64.7 & 5 & 35.3 \\
Percentage Mean & & 62 & & 38 \\
\hline
\end{tabular}

Source: Field Data, 2017.

Table 6 presents the mean percentage (62) of pupils (majority) agreeing to parental irresponsibility accounting for parental related causes of pupils' absenteeism at Felicomfort JHS while mean percentage of 38 (minority) disagreeing that parental related issues are responsible for their absenteeism.

\subsection{Research Question Five: What Are Parental Related Factors of Pupils' Absenteeism at Felicomfort JHS? (Parental Provision of Education Related Materials for Pupils)?}

For triangulation purposes, parents were also asked about things that they do to cause pupils' absenteeism. Therefore, with the aid of structured interview, parents were asked to respond to questions regarding the parental related factors that affected their wards' absenteeism. In all seven items were analyzed. The Issues considered include whether or not parents buy school uniforms for their wards, give money for their wards' food at school, transport and payment of extra class fees. Other issues examined were whether or not parents overburden their wards with household chores, provide them food to eat before going to school, advise them on the importance of education and assure them of catering for them at the SHS after successful completion of the JHS. Results are presented in table 7 .

Table 7. Parental related factors of pupils' absenteeism at Felicomfort JHS

\begin{tabular}{|c|c|c|c|c|}
\hline \multirow[t]{2}{*}{ Parental related cause of Absenteeism due to lack of reinforcement use } & \multicolumn{2}{|c|}{ Agree } & \multicolumn{2}{|c|}{ Disagree } \\
\hline & No & $(\%)$ & No & $(\%)$ \\
\hline I buy school uniforms for my ward. & 6 & 60.0 & 4 & 40.0 \\
\hline I do give my ward many household chores to do. & 7 & 70.0 & 3 & 30.0 \\
\hline I do not always give my ward money to buy food and pay for her extra classes at school. & 6 & 60.0 & 4 & 40.0 \\
\hline I always feed my ward every day before going to school. & 5 & 50.0 & 5 & 50.0 \\
\hline I don't have money to give my ward for transport every day to school. & 3 & 30.0 & 7 & 70.0 \\
\hline $\begin{array}{l}\text { I told my wards that I would be catering for them at the SHS when they successfully } \\
\text { completed the JHS }\end{array}$ & 5 & 50.0 & 5 & 50.0 \\
\hline I do not advice my ward on the importance of education & 8 & 80.0 & 2 & 20.0 \\
\hline Percentage Mean & & 57 & & 43 \\
\hline
\end{tabular}

Source: Field Data, 2017. 
Table 7 presents findings from parents' responses on how their provision of education materials and reinforcement to their children affected their absenteeism. Majority (6 parents) representing 60 percent agreed that they usually buy school uniforms for their wards while $4(40 \%)$ of them said otherwise.

\subsection{Factor Analysis of Factors of Pupils' Absenteeism}

In order to establish factors that were most responsible for pupils' absenteeism at Felicomfort JHS, factor analysis of the variables involved was done and the results presented in table 8 .

Table 8 . Factor wise analysis for the questionnaires filled by respondents

\begin{tabular}{llll}
\hline No & Factor & $M$ & $S D$ \\
\hline 1 & Stay with single parent & 3.74 & 0.87 \\
2 & Parents don't buy uniforms & 3.07 & 0.92 \\
3 & Parents don't give wards money for food and extra classes & 3.52 & 0.92 \\
4 & Parents don't pay for wards' transport & 3.71 & 0.90 \\
5 & Parents don't advice wards about school importance & 3.73 & 0.84 \\
6 & Parents can't cater for wards at secondary school & 3.60 & 0.88 \\
7 & No food at home & 3.63 & 0.91 \\
8 & Teachers canning pupils & 3.01 & 0.64 \\
9 & Teaching not to the understanding of pupils' & 2.22 & 0.54 \\
10 & Teachers finding out from pupils about their absenteeism & 3.07 & 0.77 \\
11 & Teacher failure to visit parents of absent pupils at home & 3.52 & 0.70 \\
12 & Teachers being too strict & 2.9 & 0.82 \\
13 & Teachers not showing love and care & 3.0 & 0.74 \\
14 & Teacher failure to advice pupils on education importance & 3.71 & 0.81 \\
15 & Pupils not interested in studies & 2.70 & 0.64 \\
16 & Pupils feel lazy & 2.60 & 0.51 \\
17 & Peer influence & 3.63 & 0.68 \\
18 & Pupils can't concentrate on studies & 2.65 & 0.84 \\
19 & Pupils can't wake up early for school & 2.73 & 0.52 \\
20 & Pupils always play computer games & 2.72 & 0.74 \\
\hline
\end{tabular}

Source: Field Data, 2017.

The table 8 presents the mean score and standard deviations of the factors causing absenteeism. There were 20 factors examined based on the opinions of pupils, parents and teachers.

\section{Discussion of Results}

The purpose of this study was to examine the factors affecting pupils' absenteeism at Felicomfort JHS in the Cape Coast Metropolis. The following discussions are based on the findings of the study.

Averagely for two weeks per Table 2, each pupil attended school for only 3 days. This result confirms Loren's (2011), claim that there is a significant drop in pupils' regular school attendance across the world and if not arrested early enough could lead to school dropout. Therefore, if solution is not found to the problem of absenteeism at Felicomfort JHS most of them could drop out of school.

In fact, as presented in Table 3, the contribution of pupil related factors to absenteeism is negligible (24\%). The mean percentage value of 76 percent may attest to the fact that other factors rather than pupils' attitudes like feelings lazy to attend school, inability to do homework, not interested in school and unable to wake up early to prepare for school are responsible for absenteeism. This means that in our bid to curtail pupils' absenteeism at Felicomfort JHS, the focus should not only be on reforming pupils but should largely be on provision of their educational needs. These findings are at variance to that of Loren (2011), whose study on pupils' absenteeism revealed that 71 percent of pupils' school absenteeism was partly attributed to their attitudes. Loren (2011) therefore, concluded that behaviour modification strategies should aim at attitude changing of pupils. These contradictory findings could be attributed to differences in the research settings, geographical, social and cultural differences of respondents.

As pointed out earlier in the table 4 , the percentage mean $(57.0 \%)$ of pupils disagreed that teacher related factors are responsible for their absenteeism. This finding contradicts that of Loren (2011) and Demir, Akman and Karabeyoglu (2015) who found 70 percent and 83 percent of pupils' absenteeism were due to teacher attitude. These contradictory findings could be due to differences in respondents and geographic environments in which 
these studies were conducted. However, 71.4 percent of pupils attributed their absence from school to teachers' inability to care and be interested in finding out about their reasons of not regularly attending school. These findings are in line with Maslow's (1943) need theory (as cited in Aggarwal 1995) which states that if psychological needs like show of interest, care, love and attention are giving to people including school pupils, they would be motivated to always show desirable behaviours. In this case regular school attendance.

As depicted in table 5, 80 percent of teachers admitted that they did not sometimes visit parents of absentees in their classes to find out from their parents at home about reason for their wards' absenteeism. This finding confirms that of parents' as pointed out earlier. In a similar vein, 80 percent of teachers also admitted that they usually do not find out from the absentees reasons for their absenteeism.

However as discussed earlier, 71.4 percent of pupils attributed their absence from school to teachers inability to care and be interested in finding out about their reasons of not regularly attending school. Furthermore, $70 \%-90 \%$ of responses from respondents showed that teachers always educate pupils on the importance of education, teach for pupils' understanding and do not always beat pupils for wrong doing. These findings buttress views Maslow (1943), (as cited in Aggarwal, 1995), that if psychological needs like show of interest, care, love and attention are giving to people including school pupils, they would be motivated to always register the right kind of behaviours expected from them.

Table 6 shows that majority (64.7\%-57.1\%) of the pupils attributed absenteeism to their parents' inability to educate them on the importance of education, give them money for food and pay for extra classes and give them food to eat before going to school. Other issues pointed to the fact that 57.4 percent and 57.1 percent of pupils blamed their absenteeism on parents overburdening them with too many household chores and failing to buy them school uniforms. This finding is in sharp contrast to Demir, Akman and Karabeyoglu (2015), who found only $22 \%$ of absenteeism emanating from parental or family factors. These conflicting findings could be due to differences in respondents' characteristics and geographical locations.

Per the findings of this study, to curb the problem of school pupils' absenteeism, parents have to be sensitized to the importance of education and its benefits for their wards future success. This would help them see reason in providing the basic necessities for their wards. These include money for food, school uniforms, and bags, educating their school children about the importance of education and refraining from overburdening their children with too many household chores.

In fact, findings from table 7 on parental responses to the questionnaire, contradict what their wards said about the same issue as discussed earlier. About 57.1 percent, of pupils said their parents did not buy them school uniforms while 42.9 percent of them admitted that their parents usually buy them school uniforms. In a similar vein, parents' responses pointed to the fact that their wards' absenteeism could be attributed to their (parents') inability to educate their children on the importance of education, give them money for food, pay for extra classes and transport to school. In addition, 70 percent of parents admitted that they give their wards household chores. These findings regarding parents are in line with Loren (2011), who found that 81 percent of school pupils' absenteeism was caused by parental neglect and failure to provide basic educational needs of their wards.

The findings also indicate that the heaviest chunk of the problem of absenteeism at Felicmfort Islamic JHS is attributable to parents' inability to meet financial needs and expectations of their children. The findings are also in tandem with Vroom's (1964), expectancy theory which says that people's motivation to engage in a desired activities would be negatively affected if they do not believe that they will get something of value for doing what is desirable, and their efforts will certainly result in getting what they expect. This means that to curtail the problem of school pupils' absenteeism, parents have to advice their wards about the value of education and provide them with that they need for school.

According to Table 8 on factor analysis, mean scores above 3.0 was taken as cut score off point for significance or otherwise of a factor. This is in line with (Abdullah \& Akhtar, 2016; Abdullah, Raza, \& Akhtar, 2015) (as cited in Abdul, Nauman. \& Majida, 2017)) who had pegged mean score at 3.0 as cut off point. This therefore, means that scores above 3.0 were considered as significant. Based on this criterion, all factors except teachers not teaching to the understanding of pupils and pupils' related factors are significant contributors to the problem of absenteeism. Pupils according to the Table 8, outlined 12 factors as significant contributory factors to their problem of absenteeism. However, the most significant of all these factors was parental related factors with $\mathrm{M}=$ 3.74, $\mathrm{SD}=0.87, \mathrm{M}=3.07, \mathrm{SD}=0.92, \mathrm{M}=3.52, \mathrm{SD}=0.92, \mathrm{M}=3.71, \mathrm{SD}=0.90, \mathrm{M}=3.73, \mathrm{SD}=0.94$ and $\mathrm{M}=3.63$, SD 91. 


\subsection{Summary of Key Findings}

Habitual absenteeism has been a serious problem for many schools. It adversely affects teaching as teachers would have to repeat some vital lessons for the sake of absentees hence affecting the smooth flow of lessons. Based on the investigation, the following findings emerged:

1) Many pupils (50\%) lived with single parents. This could be one of the causes of absenteeism as most single parents alone could not adequately cater for the educational needs of pupils. The thrust of the problem of absenteeism according to the findings was weak economic standing of most parents.

2) Majority of respondents (71\%) disagreed that pupils' attitudes were part of the contributory factors to pupils habitual absenteeism.

3) The overall percentage mean of pupils (58\%) disagreed that teacher factor was responsible for their absenteeism. However, 71 percent blamed their absenteeism on teachers' inability to care and find out from them the cause(s) of their continuous absence from school.

4) Majority (70\%) of the respondents agreed that parents' inability to provide educational materials, food, and paying for extra classes were the major causes of pupils' absenteeism.

\section{Conclusions and Recommendations}

The study revealed that parental neglect, inability to provide physical and educational needs of pupils form the biggest cause of pupils' school absenteeism followed by teachers' inability to pay attention to absentees, visit them and their parents at homes, find out the cause of their absenteeism, and educate them on the importance of education among others. Pupils' related factors of absenteeism include among others; peer influence, inability to wake early and prepare for school, and excessive play of computer games.

On the basis of the findings of the study, the following conclusions are made: pupils expect parents and teachers to show interest in them, educate them on the importance of education and its prospects, provide them with all the basic educational materials that they need, feed them well before going to schools in the morning and give them money for food at school as a way of motivating them to attend school regularly.

\subsection{Recommendations}

Based on the key findings and conclusions of this study, the following recommendations are made.

1) The government through the district assemblies should offer some financial assistance to poor parents and single parents to enable them adequately cater for their wards at school, offer scholarships to brilliant but needy pupils who come from poor homes to enable them regularly attend school.

2) Parents should be sensitized by School Management Committee (SMC) to the need to provide all the basic educational materials that their wards need for school.

3) Teachers of basic schools should always show interest in their pupils, especially those who usually absent themselves from school by getting to know their homes, parents and find out from them exactly the cause(s) of their absenteeism. If this is done, pupils will feel that their teachers care about them, and will be motivated to be regular at school.

4) School pupils should be counselled to avoid bad companies and realise that education is key to their good future and should therefore eschew absenteeism.

5) School heads, teachers and parents should endeavour to know and understand pupils' needs and meet them as a means of motivating them increase their good acts and behaviours including regular school attendance.

\section{References}

Abdul, Q., Nauman, A. A., \& Majida, K. (2017). Factors causing absenteeism among the students of secondary level schools. Retrieved http://pu.edu.pk/images/journal/HistoryPStudies/PDF_Files/1_V-30-No1-Jun17.pdf

from

Aggarwal, J. C. (1995). Essentials of educational psychology. New Delhi: Vikas Publishing House PVT Ltd.

Cetin, H., \& Cok, F. (2011). Parental monitoring of adolescents: a review. Cocuk ve Genclik Ruh Sagligi Dergisi, $18(3), 223-234$.

Clark, J. G. (2008). Examining truancy board effectiveness in countering student absenteeism in grades K-5 in three title I schools in Northeast Tennessee. Published Doctoral Dissertation, East Tennessee State University, UMI Number: 3308020. 
Demir, K., \& Akman Karabeyoglu, Y. (2015). Factors associated with absenteeism in high schools. Eurasian Journal of Educational Research, 62, 37-56. https://doi.org/10.14689/ejer.2016.62.4

Felicomfort, JHS. (2016). Felicomfort JHS attendance records. Amamoma: Cape Coast.

Hamm, J. V., \& Faircloth, B. S. (2005).The role of friendship in adolescents' sense of school belonging. New Directions for Child and Adolescent Development, 107, 61-78. https://doi.org/10.1002/cd.121

Heyne, D., Gren-Landell, M., Melvin, G., \& Gentle-Genitty, C. (2018). Differentiation between school attendance problems: Why and How? Cognitive and Behavioral Practice. https://doi.org/10.1016/j.cbpra.2018.03.006

Johnmarshal, M. (2009). Chronic school absenteeism and the role of adverse childhood experiences. Retrieved from https://www.ncbi.nlm.nih.gov/pubmed/28927940

Loren, M. (2011). Action research on student and pupil absenteeism in school. Retrieved from https://owlcation.com/academia/action-research-on-student-absenteeism

Lussier, R. N., \& Achua, F. C. (2001). Leadership; theory, application, skill development. New York: South-Western Publishing.

Maslow, A. (1943). Maslow on Management. New York: Wiley.

Myers, D. G. (2008). Exploring psychology (7th ed.). New York: Worth publishers.

Nkansah, N., Ninson, S., Owusu, B. F., \& Prempeh, O. L. ( 2017). The impact of absenteeism on the academic performance of pupils of Ebom-Bomfa JHS. Unpublished dissertation. University of Cape Coast.

Pehlivan, G. (2006). The school absenteeism among high school students: contributing factors.

Pullen, P. L. (2004). Brighter beginnings for teachers. Lanham, MD: Scarecrow Education.

Rebore, R. W. (2007). Human resources administration in education. Boston: Ally and Bacon.

Robinson, L. (2009). The association of obesity and school absenteeism attributed to illness or injury among adolescents in the United States. Retrieved from https://www.sciencedirect.com/science/article/pii/S1054139X12001486

Sarantakos, S. (1998). Social research. London: Macmillan. https://doi.org/10.1007/978-1-349-14884-4

Scanvenger V. (2011). Absenteeism. Retreived Jully 11, 2016, from http://www.businessdictionary.com/definition/absenteeism.html\#ixzz4E8tJSJqS

Spring, L. (1997). Uses and users of information. Retrieved from https://www.ischool.utexas.edu/ ssoy/usesusers/1391d1b.htm

Vroom, V. (1964). Work and motivation. New York: John Wiley \& Sons.

Wall, L. (2000). Factors associated with absenteeism in high schools. Retrieved from http://www.ejer.com.tr/0DOWNLOAD/pdfler/tr/kademir62.pdf

Wallen, N. (2006). Teacher absenteeism in Turkish primary schools: a qualitative perspective from school principals. $\quad$ Retrieved http://citeseerx.doi.org.ist.psu.edu/viewdoc/download?=10.1.1.662.9053\&rep=rep1\&type=pdf

\section{Copyrights}

Copyright for this article is retained by the author, with first publication rights granted to the journal.

This is an open-access article distributed under the terms and conditions of the Creative Commons Attribution license (http://creativecommons.org/licenses/by/4.0/). 